\title{
Lead isotope composition and host phases in airborne particulate matter from Budapest, Hungary
}

\section{Péter Sipos, Tibor Németh}

Institute for Geological and Geochemical Research, Research Centre for Astronomy and Earth Sciences, Hungarian Academy of Sciences, Budapest

\section{Viktória Kovács Kis}

Institute of Technical Physics and Materials Science

Research Centre for Natural Sciences,

Hungarian Academy of Sciences, Budapest

Lead is a frequent, potentially toxic pollutant of the urban environment. Its risk assessment in airborne particulate matter requires data both on its speciation and potential sources. In this paper we present results of a detailed mineralogical (XRD and TEM) and geochemical (selective chemical extractions and lead isotope ratio analyses) study of total suspended particulate (TSP) matter samples from Budapest, Hungary, to fulfill these requirements.

Total lead concentrations showed significant enrichment in the studied TSP samples as compared to its geochemical background value. It could be associated with several host phases. The potentially mobile fraction of lead, which could also be harmful to humans, can be as high as $16 \%$ of the total lead. This is represented by $\mathrm{Pb}$ sorbed on the surface of clay minerals and in the form of carbonates (and sulfates). On the other hand, between 20 and 30\% of total lead of TSP material is hosted by magnetite, a highly resistant mineral. However, its rapid oxidation during combustion processes to hematite and/or weathering in the acidifying urban environment to ferrihydrite, may result in the enhanced mobilization of lead.

The lead isotope composition of the TSP samples suggests the mixing of several sources for this metal, with slight variation among the sampling sites. Despite the phasing out of leaded gasoline, its contribution to the $\mathrm{Pb}$ content of the TSP was observed. Our data also supported that the presence of lead of gasoline origin decreases in the airborne TSP during the last decade in Budapest. Another important source for lead is found to be coal combustion linked to domestic and industrial heating. Lead isotope ratio data suggest additional source(s) for this metal, at least in certain localities, but further investigations are necessary to specify them.

Key words: total suspended particulates, air pollution, heavy metal, lead, isotopes

\author{
Addresses: P. Sipos, T. Németh: H-1112 Budapest, Budaörsi út 45. Hungary \\ e-mail: sipos@geochem.hu \\ V. Kovács Kis: H-1121 Budapest, Konkoly-Thege M. út 29-33. Hungary \\ Received: March 29, 2013; accepted: July 15, 2013
}




\section{Introduction}

Studies on sources, compositions, and distribution of airborne particulate matter components are necessary for their risk assessment of atmospheric quality, ecology and human health. This is especially true for the urban environment, where population and traffic density are relatively high, and a harmful effect of airborne particulate matter is expected to be significantly increased (Vardoulakis et al. 2003).

Lead is one of the potentially toxic metals showing significantly high enrichment in the urban particulate matter (Braun et al. 2007). The most important source of this metal was vehicular traffic, until the phase-out of leaded gasoline, which resulted in a decrease of lead concentration in urban aerosol, as was also shown in Budapest (Salma et al. 2000). However, vehicles still expel Pbcontaining phases into the environment (Zajzon et al. 2013), as this metal can be found in lubricating oil and grease, and is also the common component of bearings, tires and break linings. Lead may also originate from domestic and industrial combustion for heating purposes and is the common component of construction materials and the built-up environment as well (Sutherland 2000). Therefore, lead is widely distributed in the exposed urban environment due to the long history of its emission from anthropogenic sources. Analysis of the composition of airborne particulate matter indicates that a portion is composed of soil that has been resuspended and that it has the capability of entraining significant volumes of $\mathrm{Pb}$ into the air of urban areas (Laidlaw and Filippelli 2008).

Owing to the fact that lead may have originated from several sources in the urban environment, its form within the different environmental matrices shows large variation. Although lead is often associated with magnetic particles in the urban environment (Gautam et al. 2005), several studies showed that a significant proportion of this metal can be dissolved by weak acids (Duong and Lee 2009). Sequential chemical extraction of lead from urban dust samples showed that, beside the residual phases, oxidizable, reducible and easily extractable fractions may also contain high amounts of lead (Banerjee 2003). These findings correspond to the observations of Barrett et al. (2010) who found that Pb occurs primarily in the form of $\mathrm{Pb}$-sorbed goethite, as well as lead chloride, carbonate, oxide and phosphate in urban dust.

Knowing only the total concentrations and chemical forms of $\mathrm{Pb}$ is not sufficient for a precise evaluation of contamination sources. As each source of $\mathrm{Pb}$ can have distinct or sometimes overlapping isotope ratio ranges, lead isotope studies can provide a convenient approach for studying and tracing sources of $\mathrm{Pb}$ pollution in different environmental matrices (Komárek et al. 2008).

The risk assessment of lead in airborne particulate matter requires data both on speciation and potential sources of this metal. Correspondingly, our goals were (i) to identify the host phases of lead in total suspended particulate matter by detailed mineralogical analyses and selective chemical extractions, and (ii) to 
provide data on the potential sources of pseudo total (aqua regia-soluble) lead by isotope ratio analyses.

\section{Materials and methods}

Total suspended particulate (TSP) matter samples were collected from the air filters placed in the respiration channels used for the air supply of methaneheated turbines in four thermal power stations in Budapest (Fig. 1). The $60 \times 60$ $\mathrm{cm}$-large textile filters are in use until their transmission is high enough, generally for a few months or even up to a year. Such a filter may transmit more than one million $\mathrm{m}^{3}$ of air monthly. They are generally placed at 5-15 m height so the contribution of local soil to TSP material is minimal. As compared to other urban environments, however, contribution of soot and carbonaceous particles may be overrepresented with this sampling method due to the by-products of methane combustion in the thermal power stations. Altogether the 9 samples were collected from the following filters from four sampling sites (with the application times and periods in parentheses). Four filters from the Kelenföld station: KF1

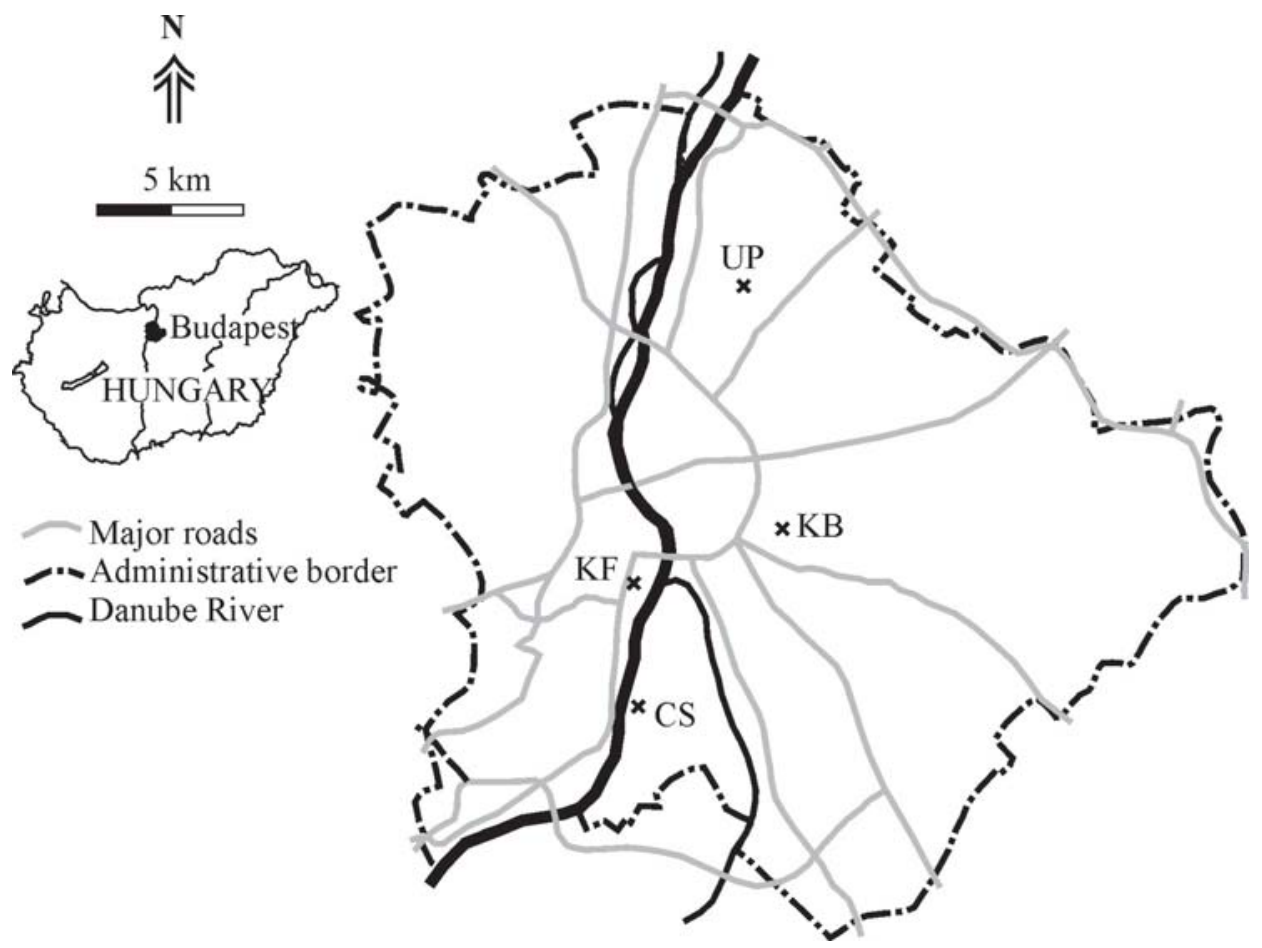

Fig. 1

Sketch map showing the localities of the thermal power plants, namely Csepel (CS), Kóbánya (KB), Kelenföld (KF), Újpest (UP) 
(used for 3 months in the summer of 2010), KF2 (used for 3 months in the summer of 2010), KF3 (used for 6 months between June and December of 2010), KF4 (used for 6 months between June and December of 2010); two filters from the Kőbánya station: KB1 (used for 13 months between July of 2009 and August of 2010), KB2 (used for 6 months between April and October of 2010); 2 filters from the Ujpest station: UP1 (used for 11 months between January and December of 2010), UP2 (used for 6 months March and August of 2010); and 1 filter from the Csepel station (used for 15 months between April of 2010 and July of 2011). As the filters were in use at different date and time periods, with varying overlap, the samples cannot be used for comparison of spatial or temporal changes of TSP characteristics in Budapest. However, they are assumed to give a good outline of the general characteristics of TSP for Budapest. Samples were removed from the filters mechanically. Large plant and animal debris were removed by passing the TSP through a $2 \mathrm{~mm}$ sieve. Before the chemical analyses, samples were powdered in an agate mortar to obtain a particle size smaller than 10 micrometer.

Loss on ignition (at $450{ }^{\circ} \mathrm{C}$ and $1050{ }^{\circ} \mathrm{C}$ ) was studied using a MOM derivatograph (Institute for Geological and Geochemical Research). The bulk samples were characterized for their mineralogical composition with a Philips PW 1710 X-ray diffractometer (XRD) (Institute for Geological and Geochemical Research). Phase composition of the bulk soil was estimated on randompowdered samples by semi-quantitative phase analysis after the method of Bárdossy et al. (1980). High-resolution transmission electron microscopy (HRTEM) and selected-area electron diffraction (SAED) analyses were carried out to characterize the mineralogical and chemical composition of individual mineral particles in the samples with special emphasis on those containing lead. The samples were suspended in ethanol, and then dropped onto a wholly carboncoated $\mathrm{Cu}$ grid for the analyses. The measurements were performed on a Philips CM 20 TEM with a LaB6 filament, equipped with a Noran energy dispersive spectrometer (EDS) (Institute of Technical Physics and Materials Science). For the chemical analyses a $20 \mathrm{~nm}$ spot size and counting times of $100 \mathrm{~s}$ were used. The relative standard deviations of the EDS analyses are below $2.5 \%, 10 \%$ and $50 \%$ for element concentrations $>10 \mathrm{wt} \%, 1-10 \mathrm{wt} \%$, and $<1 \mathrm{wt} \%$, respectively. We intended to analyze only one discrete particle in each case, which could be confirmed from the corresponding diffraction pattern.

The chemical composition of the bulk samples was analyzed with a Philips PW2404 X-ray fluorescence spectrometer (Pannon University, Veszprém, Hungary). The powdered samples were homogenized with $20 \mathrm{wt} \%$ of boric acid as a binding material under ethanol and were pressed in aluminum rings at 10 $\mathrm{t} / \mathrm{cm}^{2}$. The standard deviations of the analyses were generally below $5 \%$ and $10 \%$ for major elements and lead, respectively. Selective chemical extractions were also carried out to study the mobilization conditions of lead on parallel samples in each case, with standard deviations generally below $10 \%$. Water-soluble amounts of lead were determined from $2.5 \mathrm{~g}$ samples and $25 \mathrm{ml}$ of distilled water at $21^{\circ} \mathrm{C}$ 
with continuous agitation. The solution was filtered and analyzed with a PerkinElmer Elan 9000 ICP-MS instrument (AcmeLabs, Vancouver, Canada) for its $\mathrm{Pb}$ content. Aqua regia digestion was carried out on $0.5 \mathrm{~g}$ sample with $12 \mathrm{ml}$ aqua regia in the heating block of a hot water bath at $95{ }^{\circ} \mathrm{C}$ for 1 hour. Before evaporation the cooled sample was made up to $10 \mathrm{ml}$ with dilute hydrochloric acid. Concentrations of lead isotopes ${ }^{204} \mathrm{~Pb},{ }^{206} \mathrm{~Pb},{ }^{207} \mathrm{~Pb}$ and ${ }^{208} \mathrm{~Pb}$ ) in the solutions were analyzed with a Perkin-Elmer Elan 9000 ICP-MS instrument. The quality of the $\mathrm{Pb}$ isotopic analyses was checked by the study of two standard reference materials (SRM). Analyzed and expected concentrations for the NIST981-1Y SRM are 0.29 and $0.29 \mathrm{mg} / \mathrm{kg}$ for ${ }^{204} \mathrm{~Pb}, 4.91$ and $4.83 \mathrm{mg} / \mathrm{kg}$ for ${ }^{206} \mathrm{~Pb}, 4.45$ and $4.42 \mathrm{mg} / \mathrm{kg}$ for ${ }^{207} \mathrm{~Pb}$, and 10.68 and $10.47 \mathrm{mg} / \mathrm{kg}$ for ${ }^{208} \mathrm{~Pb}$, respectively. Analyzed and expected concentrations for the NIST-983-1Y SRM are $<0.01$ and $0.007 \mathrm{mg} / \mathrm{kg}$ for ${ }^{204} \mathrm{~Pb}, 18.72$ and $18.43 \mathrm{mg} / \mathrm{kg}$ for ${ }^{206} \mathrm{~Pb}, 1.38$ and $1.31 \mathrm{mg} / \mathrm{kg}$ for ${ }^{207} \mathrm{~Pb}$, and 0.32 and $0.25 \mathrm{mg} / \mathrm{kg}$ for ${ }^{208} \mathrm{~Pb}$, respectively.

Two more chemical extractions were also carried out to study the potential toxicity of lead for humans. They are supposed to simulate the neutral lung (Niu et al. 2010) and the acidic stomach environment (Mercier et al. 2002), respectively. In the first one, $25 \mathrm{ml} 0.01 \mathrm{M}$ ammonium-acetate was added to $2 \mathrm{~g}$ of samples and reacted for 2 hours at $37^{\circ} \mathrm{C}$ with occasional agitation. In the second one, $25 \mathrm{ml}$ dilute acetic acid (6 ml glacial acetic acid in 81 of distilled water) was added to $2 \mathrm{~g}$ of samples; the $\mathrm{pH}$ of the suspension was adjusted to $\mathrm{pH} 2$ with addition of $12 \mathrm{M}$ hydrochloric acid. The extraction was carried out for 6 hours at $37^{\circ} \mathrm{C}$ with occasional agitation. In both cases, the solution was separated by centrifugation at $3500 \mathrm{rpm}$ for 20 minutes. The concentration of lead in the solutions was analyzed using a Perkin Elmer Analyst 300 AAS instrument (Institute for Geological and Geochemical Research).

\section{Results}

\section{Samples characterization}

The major element composition of the samples is shown in Table 1. As compared to the geochemical background values for Hungary (Ódor et al. 1997), the samples show significant enrichment in S, Na and K. The high amount of sulfur may originate from construction materials (gypsum) or from the reaction between sulfuric acid and sulfate-forming cations (e.g. K or $\mathrm{Ca}$ ) in the urban air (Panigrahy et al. 2003), and may also reflect the presence of organic material (plant and animal remains) in the samples. Sodium enrichment can be due to the extended use of halite as a de-icing agent. The presence of both gypsum and halite was also proved by the mineralogical analyses: gypsum (around $5 \mathrm{wt} \%$ ) was identified in each sample whereas halite appeared only in the KF1 sample (nearly $10 \mathrm{wt} \%$ ) by X-ray diffraction (XRD) analyses (Fig. 2).

The relatively high loss on ignition (LOI) values (between 21 and $37 \mathrm{wt} \%$ ) show the presence of a large amount of volatile components in the samples (Table 1). 
44 P. Sipos et al.

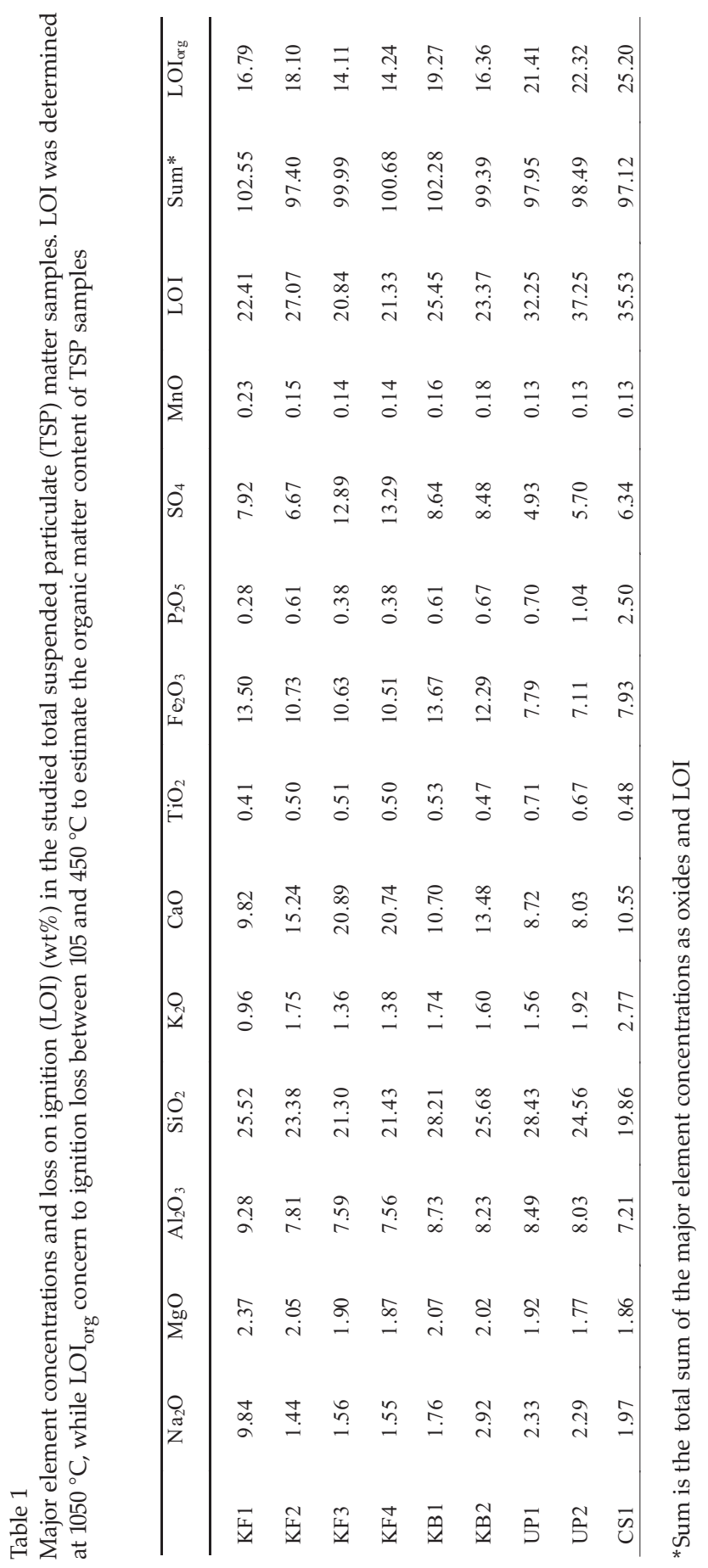

Central European Geology 56, 2013 


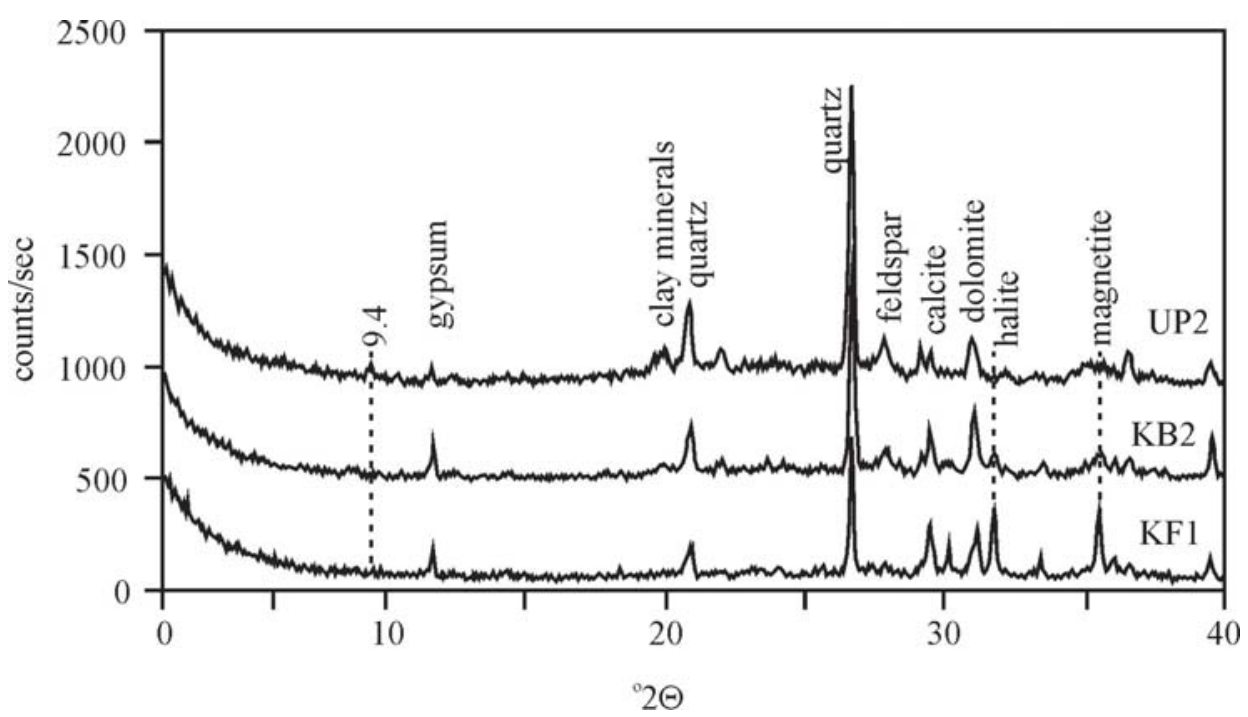

Fig. 2

Characteristic X-ray diffractograms showing the major components of some bulk particulate matter samples (KF1 - Kelenföld, KB2 - Kóbánya, UP2 - Újpest)

The LOI values between 105 and $450{ }^{\circ} \mathrm{C}$ provide a rough estimate for the organic matter content of geologic materials (Craft et al. 1991). These values for the studied samples suggest that their organic matter content is expected to be between 14 and $25 \mathrm{wt} \%$. This corresponds to the results of XRD analyses, with which a large amount of amorphous phases were identified. They can be due to the expected presence of organic material and soot. Transmission electron microscopic (TEM-EDS) analyses showed that soot aggregates consisting of nanosized (few tens of $\mathrm{nm}$ ) soot particles are common phases in the studied TSP samples (see Fig. 3a). Soot is a common anthropogenic component of urban airborne particulate matter resulting from different combustion processes (vehicle, heating, industrial, etc.) (Grobéty et al. 2010).

The bulk mineralogical composition of the samples is dominated by the presence of minerals characteristic of the geologic environment of the sampling sites (Fig. 2). The samples consist mostly of 15-20 wt\% quartz, 5-20 wt\% carbonates, 5-10 wt $\%$ clay minerals and 5-10 wt\% (plagioclase) feldspar. Carbonate phases are represented by nearly similar amounts of calcite and dolomite, with probable Fe and Mn substitution in the latter. Among the clay minerals illite predominates, but chlorite and smectite also appear. Such phases are characteristic natural components of urban dust, representing primarily the most rapidly deposited fraction (Farkas and Weiszburg 2006; Grobéty et al. 2010).

Dominant typically anthropogenic phases in the samples were found to be the iron oxides. Our XRD analyses showed the presence of large amounts of 
magnetite (5-10 $\mathrm{wt} \%)$ at most of the sampling sites, except in the UP samples (Fig. 2). This phase was also shown by our TEM-EDS analyses (Fig. 3b), together with ferrihydrite and hematite (Fig. 3c), but the frequency of the latter two phases was much lower than that of magnetite. They can be the oxidation/weathering products of magnetite. The oxidation may already have occurred in the anthropogenic combustion process, as suggested by the results of Zajzon et al. (2013), who found a close association of magnetite and hematite in vehicle exhaust samples. Besides gypsum and halite, mentioned earlier, further metal oxides and carbonates were found sparingly by TEM-EDS (one single franklinite, a smithsonite and a $\mathrm{ZnO}$ particle were found in the UP1 sample).

\section{Lead in the samples}

The total concentration and the amount of lead mobilized by the different chemical extractions are shown in Table 2. The total lead concentrations of the samples are higher by 1-2 magnitudes than the geochemical background concentration of lead in Hungary (21 mg/kg; Ódor et al. 1997). Samples from the KF site are characterized by the highest lead concentrations (between 1953 and $5942 \mathrm{mg} / \mathrm{kg}$ ), while other samples contain amounts of this metal (between 368 and $942 \mathrm{mg} / \mathrm{kg}$ ) a magnitude lower. Total lead concentrations do not show linear correlation with any major chemical component of the TSP material. Between 14

Table 2

Total lead concentration and the amount of lead mobilized by different extractions used $(\mathrm{mg} / \mathrm{kg})$ Lung test was carried out with weak ammonium-acetate solution at $\mathrm{pH} \mathrm{7,} \mathrm{while} \mathrm{stomach} \mathrm{test} \mathrm{with}$ mixture of weak acetic acid and hydrochloric acid at $\mathrm{pH} 2$

\begin{tabular}{lccccccccc}
\hline & Total & \multicolumn{3}{c}{ Aqua regia } & & $\begin{array}{c}\text { Stomach } \\
\text { at } \mathrm{pH} 2\end{array}$ & $\begin{array}{c}\text { Lung } \\
\text { at } \mathrm{pH} 7\end{array}$ & Distilled water \\
\hline & $\mathrm{Pb}$ & $\mathrm{Pb}^{*}$ & ${ }^{204} \mathrm{~Pb}$ & ${ }^{200} \mathrm{~Pb}$ & ${ }^{207} \mathrm{~Pb}$ & ${ }^{208} \mathrm{~Pb}$ & $\mathrm{~Pb}$ & $\mathrm{~Pb}$ & $\mathrm{~Pb}$ \\
$\mathrm{KF} 1$ & 5942 & 2231 & 32 & 553 & 477 & 1169 & 285 & $<5$ & 3.3 \\
$\mathrm{KF} 2$ & 1923 & 1478 & 21 & 369 & 314 & 773 & 154 & $<5$ & 4.2 \\
$\mathrm{KF} 3$ & 3878 & 2874 & 41 & 716 & 610 & 1506 & 630 & $<5$ & 2.6 \\
$\mathrm{KF} 4$ & 3916 & 2990 & 43 & 754 & 638 & 1555 & 631 & $<5$ & 2.6 \\
$\mathrm{~KB} 1$ & 547 & 434 & 6.2 & 109 & 93 & 225 & 11 & $<5$ & 3.7 \\
$\mathrm{~KB} 2$ & 538 & 463 & 6.6 & 117 & 99 & 240 & 18 & $<5$ & 5.1 \\
$\mathrm{UP1}$ & 942 & 692 & 10 & 169 & 146 & 367 & 118 & $<5$ & 4.9 \\
$\mathrm{UP2}$ & 427 & 331 & 4.8 & 85 & 71 & 171 & 43 & $<5$ & 2.8 \\
$\mathrm{CS} 1$ & 368 & 267 & 3.8 & 67 & 58 & 137 & 2.8 & $<5$ & 0.4 \\
\hline
\end{tabular}

$\mathrm{Pb}^{*}=$ lead concentrations were calculated as a sum of the concentrations of each lead isotopes in aqua regia dissolution

Fig. $3 \rightarrow$

Dominant $\mathrm{Pb}$-bearing phases in the particulate matter samples. Transmission electron microscopy micrographs, diffraction patterns and EDS spectra of

(a) a $\mathrm{Zn}$ and $\mathrm{Pb}$-bearing smectite particle associated with soot aggregates composed of nano-spheres; (b) $\mathrm{Pb}$ and $\mathrm{Zn}$-bearing magnetite spheres; (c) $\mathrm{Zn}, \mathrm{Pb}$ and Mn-bearing dense aggregates of magnetite, hematite $(3.7 \AA)$ and poorly crystalline ferrihydrite 
Lead isotope composition and host phases in airborne particulate matter from Budapest, Hungary 47
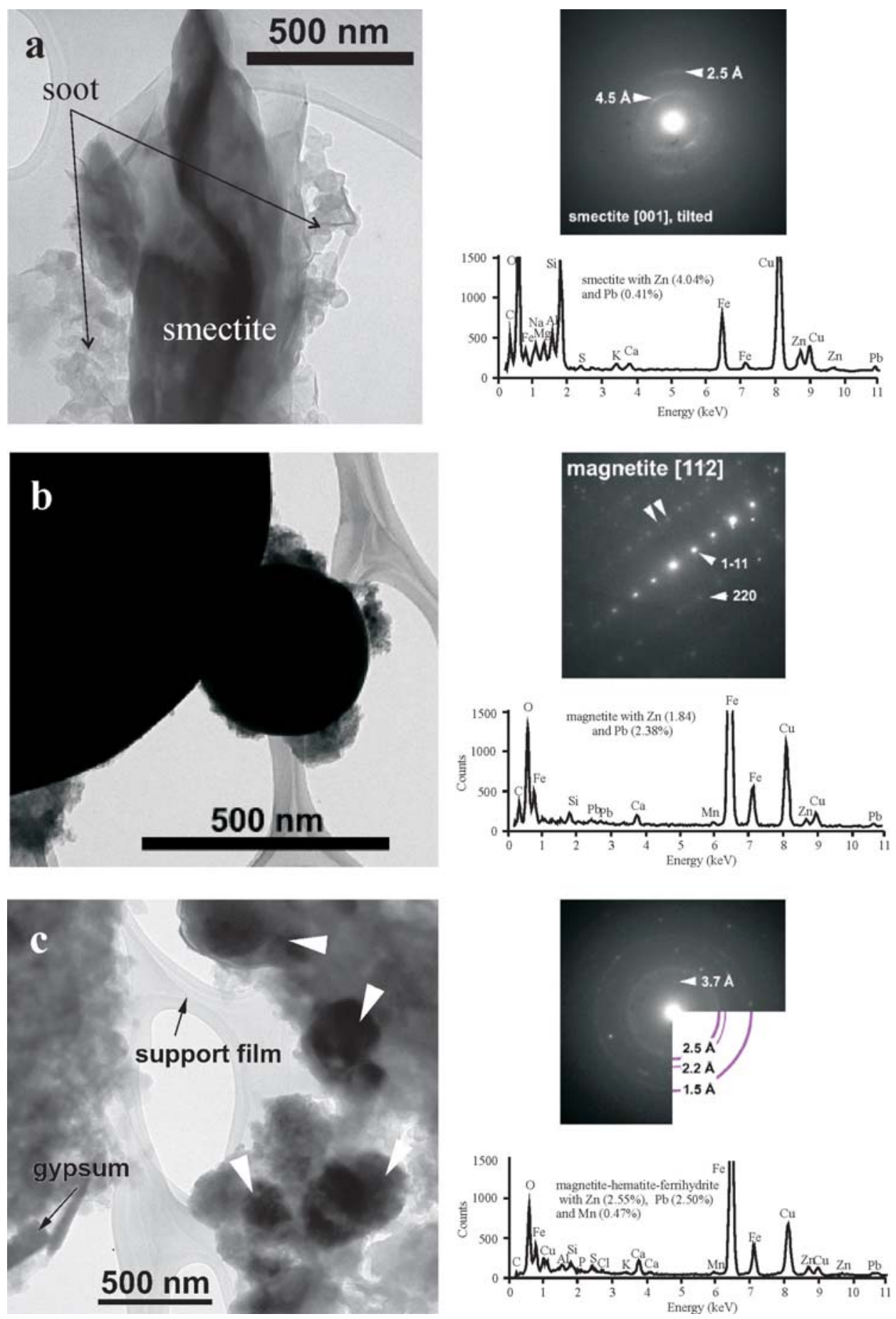

Central European Geology 56, 2013 
and $28 \%$ of total lead is insoluble in hot aqua regia, except in sample KF1, where only $38 \%$ of total lead could be extracted from the sample such a way (Fig. 4). This difference is also shown by the fact that the total and aqua regia soluble lead shows perfect linear correlation $(r=1.00 ; p<0.05)$ in most of the samples except in sample KF1 (if this latter sample is also included in the regression analysis the $\mathrm{r}$ value changes to 0.89 ). The weak acid extraction at $\mathrm{pH} 2$ (stomach test) resulted in the mobilization of $1-16 \%$ of total lead content of the samples (Fig. 4). The ratio of lead extracted by weak acid shows a large variation among the samples; its highest values are reached in two samples from Kelenföld (KF3 and KF4). In these samples the weak acid-extractable amount of lead is more than $600 \mathrm{mg} / \mathrm{kg}$, showing that even such a high $\mathrm{Pb}$ quantity is easily mobilized in an urban or in a stomach environment (Table 2). Several studies (e.g. Tokalioglu and Kartal 2006; Sutherland et al. 2012) found that weak acid-extractable lead shows a large variation among urban particulate matter samples (from a few \% up to $20-30 \%$ ). The metals extractability shows a significant increase with decreasing particle size (Sutherland et al. 2012); therefore the comparison of samples of different origin or those collected by different methods is not possible. The extraction (by $0.01 \mathrm{M}$ ammonium-acetate at $\mathrm{pH}$ 7) used for simulating the lung environment resulted in

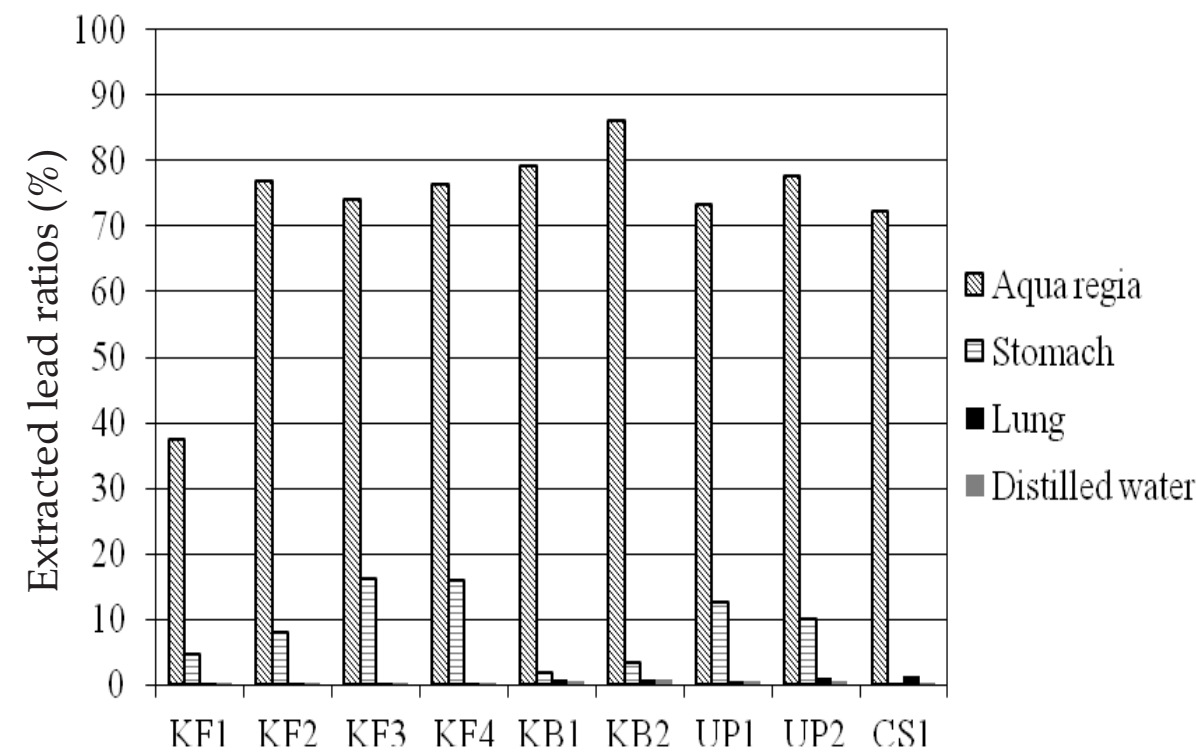

Fig. 4

Extracted lead ratios (\%) in the different chemical extractions used. The lung test was carried out with weak ammonium-acetate solution at $\mathrm{pH} 7$, and the stomach test with a mixture of weak acetic acid and hydrochloric acid at $\mathrm{pH} 2$. Note that in the lung test the extracted amount of lead was below the detection limit $(5 \mathrm{mg} / \mathrm{kg}$ ) for each sample; thus the corresponding columns show the respective ratio for this value 
lead concentrations below the detection limit for each sample (Table 2). Our data show that a very similar extraction efficiency could be reached with this reagent to distilled water for lead. The data from the latter extraction indicates that there is a very small ratio of total lead (between 0.1 and $1 \%$ corresponding to concentrations between 0.1 and $5.4 \mathrm{mg} / \mathrm{kg}$ ) in the samples which is water-soluble (Fig. 4). Although the water-soluble lead in the airborne particulate matter may show high variation, its ratio rarely exceeds $10 \%$ of the total lead (e.g. Fernandez Espinosa et al. 2002; Feng et al. 2009).

According to the TEM-EDS analyses the spherular or xenomorphic magnetite particles may be the most important Pb-bearing phases in the samples (Fig. $3 b$ ). They sometimes contain 2-3 wt $\%$ of $\mathrm{Pb}$ (and also a similar amount of $\mathrm{Zn}$ and occasionally less $\mathrm{Mn}$ ). This has also been observed by several authors (e.g. Gautam et al. 2005) who found a significant linear relationship between magnetic susceptibility (primarily due to magnetite) and $\mathrm{Pb}$ content of urban particulate matter. The magnetite particles often form aggregates and are closely associated with soot and/or clay minerals. In samples with high magnetite content (primarily the KF samples), metal-free magnetite spherules up to a few micrometer sizes also appeared. Clay minerals (primarily smectite) may also contain a small amount of $\mathrm{Pb}$ (up to a few wt\%) (Fig. 3a). The $\mathrm{Pb}$ is probably sorbed on the surface of clay minerals in the soil, the resuspension of which may contribute to the airborne particulate matter. This is a well-documented phenomenon in the urban environment (Laidlaw and Filippelli 2008). A single aggregate consisting of magnetite and calcite was also found by TEM analyses in which the latter contained a significant amount of $\mathrm{Pb}(4.88 \mathrm{wt} \%)$ suggesting the presence of $\mathrm{Pb}$ in carbonates. Among other lead phases, $\mathrm{PbCO}_{3}$ was found as a common component of urban airborne particulate matter by others. Its presence can be due to the contribution of flying ash from fossil fuel combustion, waste incineration (Wichmann et al. 2000) or industrial (smelter) dust (Spear et al. 1998) to the urban airborne material.

\section{Lead isotope composition of the samples}

The isotopic composition of lead shows very similar distribution in the samples. The most frequent isotope of this metal is ${ }^{208} \mathrm{~Pb}(52.08 \pm 0.51 \%)$, followed by nearly similar ratios for ${ }^{206} \mathrm{~Pb}(25.06 \pm 0.33 \%)$ and ${ }^{207} \mathrm{~Pb}(21.34 \pm 0.19 \%)$, and the least frequent is ${ }^{204} \mathrm{~Pb}(1.43 \pm 0.01 \%)$. This distribution show slight differences compared to the average natural abundances of lead isotopes (DeLaeter et al. 2003). The ratio of ${ }^{204} \mathrm{~Pb}$ and ${ }^{206} \mathrm{~Pb}$ is generally higher in the studied samples than expected from their natural abundances (1.40 and $24.1 \%$, respectively), whereas that of ${ }^{207} \mathrm{~Pb}$ is lower (its natural abundance is $22.1 \%$ ). The ratio of ${ }^{208} \mathrm{~Pb}$ shows a slight variation among the studied samples: sample UP is the only one showing a higher ratio for this $\mathrm{Pb}$ isotope $(53.02 \%)$ than its natural abundance, which is $52.4 \%$. Most of the samples show similar (KF1, KF2, KF3) or slightly lower ratios 
(CS1, KF4, KB1, KB2, UP2). These slight differences are due to the mixing of several lead sources (both natural and anthropogenic) in the samples. It is important to note that lead isotope analyses were carried out after the aqua regia dissolutions of the samples; hence they do not represent the magnetite-bound lead, despite the fact that it is also supposed to be primarily of anthropogenic origin. Moreover, DeVivo et al. (2001) found that the lead isotope ratios of the acid-leachable fraction of fluvial sediments showed slightly different $\mathrm{Pb}$ isotope ratios compared to the residual fraction, which is due to the much stronger anthropogenic signal in the mobile fractions. Thus the shift of the lead isotope ratio values towards that of anthropogenic sources can also be expected in our case. The lead isotope composition of airborne particulate matter generally reflects the mixing of different sources; therefore source appointment can be quantified exactly in cases where all potential sources of $\mathrm{Pb}$ are characterized and have specific ratios (Komárek et al. 2008). Since the contribution of resuspended soil or road dust to the TSP material may be as high as 74\% (Young et al. 2002) a significant presence of lead isotope characteristics of past emission sources is expected in our case. However, the isotope composition of past sources cannot be identified; thus our evaluation is based on comparisons with data from the literature. According to their ${ }^{208} \mathrm{~Pb} /{ }^{207} \mathrm{~Pb}$ and ${ }^{206} \mathrm{~Pb} / 207 \mathrm{~Pb}$ ratios, most of the studied samples show that their lead comes from the mixing of two major sources: European leaded fuel and natural lead (Fig. 5a). This plot also shows that all the studied samples can be found between the field of urban aerosol samples collected in the 1990s in Budapest, Hungary, and that of natural lead. However, the CS1 and UP1 samples present slightly different $\mathrm{Pb}$ isotopic composition from this mixing line suggesting the contribution of additional lead sources. These two samples can be characterized by very similar ${ }^{206} \mathrm{~Pb} /{ }^{207} \mathrm{~Pb}$ ratios but significantly lower (CS1) and higher (UP1) ${ }^{208} \mathrm{~Pb} / 207 \mathrm{~Pb}$ ratios than the other samples. Sample CS1 can be characterized by the lowest, and sample UP1 by the highest ${ }^{208} \mathrm{~Pb}$ ratio among the studied samples. When other potential lead sources, such as Central European coals and ores are taken into account, the plot of ${ }^{208} \mathrm{~Pb} / 206 \mathrm{~Pb}$ vs. ${ }^{206} \mathrm{~Pb} /{ }^{207} \mathrm{~Pb}$ ratios (Fig. 5b) shows that the majority of samples can be characterized by very similar lead isotope ratios to the Central European lead ores and coals, except again the samples CS1 and UP1. If further $\mathrm{Pb}$ ore and coal sources are involved in the comparison, the plot of ${ }^{208} \mathrm{~Pb} /{ }^{206} \mathrm{~Pb}$ vs. ${ }^{207} \mathrm{~Pb} / 206 \mathrm{~Pb}$ ratios (Fig.

Fig. $5 \rightarrow$

Aqua regia-soluble lead isotope ratios of the studied total suspended particulate matter samples (Csepel - CS, Kőbánya - KB, Kelenföld - KF, Újpest - UP). Comparison of our data to

(a) the lead isotope ratio data for European leaded gasoline and natural lead (Grobéty et al. 2005), urban aerosol samples from the 1990s (Bollhöfer and Rosman 2001) and Hungarian soils (Reimann et al. 2012) (The "cleaning" trend indicated by the gray arrow is given by Tomaševic et al. (2013));

(b) the lead isotope ratio data for Central and East European lead ores and Central European coals (Komárek et al. 2008);

(c) the lead isotope ratio data for lead ores of different origin and Appalachian coals (Tarzia et al. 2002) 
Lead isotope composition and host phases in airborne particulate matter from Budapest, Hungary 51

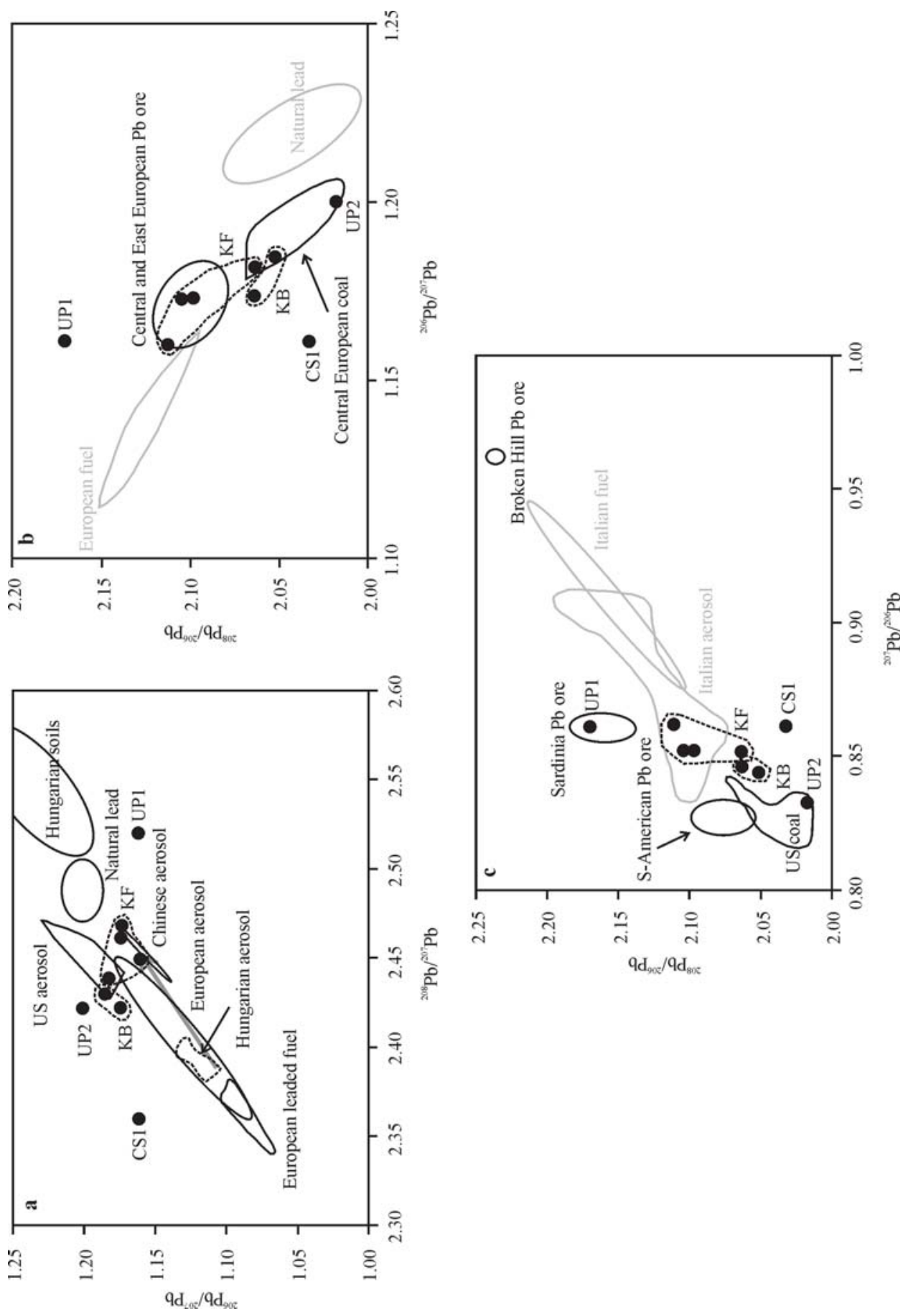

Central European Geology 56, 2013 
5c)suggests the presence of at least three anthropogenic sources for lead: coals, fuels and (Italian) lead ores. Sample UP1, one of the former outsider samples, shows the same $\mathrm{Pb}$ isotope ratios as Sardinian $\mathrm{Pb}$ ore does. However, sample CS1 still shows a slight difference in its $\mathrm{Pb}$ isotope ratios, e.g. the presence of other $\mathrm{Pb}$ source(s). Until now we have not found any literature data which could explain the unique $\mathrm{Pb}$ isotope characteristics for this sample.

\section{Discussion}

The most significant lead-bearing phase, which was also directly identified, is magnetite. Iron impurities are often found in combustibles and can convert to iron oxides, such as magnetite or hematite, depending of the burning conditions (Muxworthy et al. 2003), but they can also be related to the presence of ferrocene as a fuel additive (Braun et al. 2006). That is why several studies have revealed large concentrations of iron in anthropogenic particulate matter (generally between 5 and 15\%) and magnetite was identified as the dominant magnetic phase of Fe-rich particles (e.g. Chen et al. 2006). As this phase is a well-known mineral, which does not dissolve in aqua regia (e.g. Cohen et al. 2012), we can suppose that the aqua regia-insoluble lead in the samples can be primarily associated with magnetite. This finding can be also prevalent for the sample with a relatively low ratio of aqua regia-soluble lead (KF1), as it can be characterized as containing twice as much magnetite as other samples. The lack of a strong linear relationship between total iron and aqua regia-insoluble lead $(\mathrm{r}=0.48 ; p<0.05)$ does not contradict the close association of lead and magnetite, as iron may be present not only in magnetite, but probably also in carbonates, and $\mathrm{Pb}$-free magnetite particles were also found. On the other hand, oxidation/weathering products of magnetite, like hematite and ferrihydrite, are soluble in hot aqua regia (Silva et al. 2007). Our data do not allow estimating the contribution of the latter phases to the aqua regia-soluble lead. However, these results call to our attention that advanced oxidation of iron in anthropogenic combustion processes and/or intensified weathering of magnetite in the urban environment facilitate the release of potentially toxic components, such as $\mathrm{Pb}$ enclosed in iron oxides. Aqua regia-soluble lead shows a strong positive linear relationship with total $\mathrm{Ca}$ and $\mathrm{S}$ content of the samples $(\mathrm{r}=0.79$ for both at $p<0.05)$, but a negative one with the estimated organic matter content $(r=-0.80 ; p<0.05)$. This finding suggests the close association of $\mathrm{Pb}$ to $\mathrm{Ca}$ and $\mathrm{S}$-containing phases. Based on this, however, exact phases cannot be identified as hosts for lead due to the fact that aqua regia is a strong and effective solvent for numerous particulate matter components.

Apart from the fact that the weak acid extraction was used to model the acidic $\mathrm{pH}$ of the stomach environment in a very simplified way, it is also useful for the study the potential acidification of urban environment. X-Ray spectroscopy analyses by Barrett et al. (2010) showed several lead phases in urban dust, such as surface-sorbed lead, lead chloride, lead carbonate, lead oxide and lead phosphate, 
which are potentially soluble in weak mineral acids to varying degrees. These are mostly the same phases controlling aqueous-solid partitioning of lead in natural systems. At $\mathrm{pH} 2$ lead is not expected to be sorbed on natural mineral surfaces, and carbonate (cerussite), hydroxide, oxide and sulfate (anglesite) of lead is readily soluble while its phosphate (pyromorphite) is weakly soluble (Rickard and Nriagu 1978). Among major TSP components carbonates demonstrate complete, and clay minerals partial, dissolution at this $\mathrm{pH}$ (Köhler et al. 2003). As our TEM-EDS analyses also showed the association of lead with both clay minerals and carbonates, the mobilization of lead can be expected from these phases by this extraction. The strong positive linear correlation of weak acidsoluble lead and total $\mathrm{Ca}(\mathrm{r}=0.83 ; p<0.05)$ and $\mathrm{S}(\mathrm{r}=0.85 ; p<0.05)$ content of the samples suggest that $\mathrm{Pb}$ may also be hosted in the form of $\mathrm{Ca}$ or even $\mathrm{Pb}$ sulfates. However, our mineralogical investigations did not support this supposition, probably because of their relatively low concentration in the samples and/or their instability in the electron beam. The Ca and other (e.g. K) sulfate phases finally identified by TEM-EDS did not contain detectable amounts of $\mathrm{Pb}$ by EDS, but this finding does not completely exclude its presence in sulfates, as the detection limit of EDS is around $0.1 \%$ for any given particle. Water-soluble lead is a relatively small component of total lead in the samples but is readily available for any organism. Other studies (e.g. Fernandez Espinosa et al. 2002) attributed the water-soluble lead to the presence of this metal in the form of nitrates and/or chlorides in the airborne particulate matter samples.

Metal oxide and metal carbonate particles in the TSP may have primarily originated from anthropogenic emissions, whereas clay particles derived from the resuspension of roadside dust and urban soils. Magnetite particles are resistant to weathering, releasing their toxic components slowly into the environment (Graham et al. 1989). However, layer silicates and carbonates are much less resistant than magnetite (Vogelein et al. 2005); thus, beside water-soluble lead, they may be the potential source of mobile $\mathrm{Pb}$ in the TSP samples. The occasionally very high amount (up to $631 \mathrm{mg} / \mathrm{kg}$ ) of weak acid-extractable lead is assumed to be mobilized in the stomach environment, resulting in serious potential risk to the environment and human health.

Lead isotope analyses were carried out to study the potential sources of lead in the total suspended particulate matter samples. The most important source of this metal in airborne materials was vehicular traffic, until the phase-out of leaded gasoline, although traffic-related activities still emit lead into the environment in several ways. Thus the lead isotope ratios of a large majority of urban airborne particulate matter samples can be placed between that of leaded gasoline and natural lead (Bollhöfer and Rosman 2001). Due to the gradual phasing-out of leaded gasoline in several countries, a "cleaning" trend could be observed over the last decade, e.g. the lead isotope ratios of recent TSP materials have moved toward that of natural lead. According to Tomaševic et al. (2013), however, this "cleaning" trend can be affected by the appearance of lead of Chinese origin in the European 
markets. Additionally, the lead isotope ratio of Chinese lead ores can also be placed between that of natural lead and that of European leaded gasoline. This phenomenon was also observed in our case, e.g. the studied samples contain a much higher ratio of natural lead and/or much higher ratio of lead of Chinese origin than the airborne particulate matter collected in the 1990s in Budapest. It is important to note, however, that as the contribution of road dust and urban soil to the suspended material may be very high (up to $74 \%$; Young et al. 2002), and the urban soils also store the lead coming from past anthropogenic activity in their surface horizons (Hjortekans et al. 2008), the lead from leaded gasoline must be still present in the recent airborne particulate matter. Our data, however, suggest the presence of additional lead sources beside the two mentioned above. The majority of the samples, which mostly well fit the line between the isotopic composition of natural and gasoline lead, also show significant overlap with the $\mathrm{Pb}$ isotope characteristics of Central and Eastern European lead ores and coals, as based on data by Komárek et al. (2008). The former is expected to be the presence of past emission sources, as lead mining is minimal in this region, whereas the latter suggests the contribution of domestic and industrial coal combustion activity to the TSP of Budapest. As the Pb isotopic composition of these potential sources is also placed between that of leaded gasoline and natural lead, the contribution of these sources cannot be verified unambiguously. However, the wide use of these raw materials is evident and they cannot be excluded as potential lead sources. Two samples out of the 9 studied generally showed unique lead isotopic composition as compared to the others. One of these samples shows high similarity to Sardinian (Italy) lead ores (Tarzia et al. 2002), but the highest contribution of natural soil materials (as suggested by its highest $\mathrm{SiO}_{2}$ content) among the studied samples may also result in this unique behavior. For the other outsider sample, we could not find any literature data which could explain its unique $\mathrm{Pb}$ isotope characteristics. These data suggest the presence of additional source(s) for this metal, at least in certain localities, but further investigations are necessary to identify them. There may be numerous potential pollution sources, such as paints, mineral oils, etc., for which data are not available but cannot be excluded as potential sources of lead.

\section{Conclusions}

Total suspended particulate (TSP) matter samples from Budapest can be characterized by 1-2 orders of magnitude higher lead concentrations than expected from its geochemical background value for Hungary.

Lead was found to be associated with several host phases of very variable stability. Generally, between 20 and 30\% of total lead content of the TSP materials is hosted by magnetite, which may be the result of numerous combustion-linked anthropogenic processes. Although magnetite is a highly resistant phase to weathering, its rapid oxidation during combustion processes to hematite and/or 
weathering in the acidifying urban environment to ferrihydrite may result in the easier mobilization of lead (and its other potentially toxic components). Up to $16 \%$ of lead was found to be weak acid-soluble in the TSP materials, primarily representing $\mathrm{Pb}$ sorbed on the surface of clay minerals and in from of carbonates (and probably sulfates). This is the potentially mobile fraction of lead which could be harmful to human, as well. It was shown that the water-soluble amounts of lead in the TSP samples are negligible.

The lead isotope composition of the TSP samples suggests the mixing of several potential sources for this metal. These sources showed slight variation among the sampling sites. Despite the phasing out of leaded gasoline in Hungary in 1999, its contribution to the $\mathrm{Pb}$ content of the TSP can be still observed. However, our data show isotope ratios more similar to that of natural lead than the aerosols collected in the 1990s in Budapest did, supporting the observation that the presence of lead of gasoline origin gradually decreases in the airborne particulate matter in urban environment. Another important source for lead is found to be coal combustion, probably due to domestic and industrial heating. Our data suggest additional source(s) for this metal, at least in certain localities, but further investigation is necessary to identify them.

\section{Acknowledgements}

This project was financially supported by the Hungarian Scientific Research Fund (OTKA K76317). Balázs Major (Budapesti Erômú Zrt.) is thanked for the samples, Zsuzsanna Hartyáni (Pannon University) for the XRF analyses. Péter Sipos also expresses thanks for the support of the János Bolyai Research Scholarship of the Hungarian Academy of Sciences. The reviewers of the paper are also thanked for their helpful comments.

\section{References}

Banerjee, A.D.K. 2003: Heavy metal levels and solid phase speciation in street dusts of Delhi, India. Environmental Pollution, 123, pp. 95-105.

Barrett, J.S., K.G. Taylor, K. Hudson-Edwards, J.M. Charnock 2010: Solid-phase speciation of Pb in urban road dust sediment: A XANES and EXAFS study. - Environmental Science and Technology, 44, pp. 2940-2946.

Bárdossy, Gy., L. Bottyán, P. Gadó, Á. Griger, J. Sasvári 1980: Automated quantitative phase analysis of bauxites. - American Mineralogist, 65, pp. 135-141.

Bollhöfer, A., K.J.R. Rosman 2001: Isotopic signature for atmospheric lead: the northern hemisphere. - Geochimica et Cosmochimica Acta, 65, pp. 1727-1740.

Braun, A., F.E. Huggins, K.E. Kelly, B.S. Mun, S.N. Ehrlich, G.P. Huffman 2006: Impact of ferrocene on the structure of diesel exhaust soot as probed with wide-angle X-ray scattering and C(1s) NEXAFS spectroscopy. - Carbon, 44, pp. 2904-2911.

Braun, M., Z. Margitai, A. Tóth, M. Leermakers 2007: Environmental monitoring using linden tree leaves as natural traps of atmospheric deposition: a pilot study in Transylvania, Romania. AGD Landscape and Environment, 1, pp. 24-35. 
Chen, Y., N. Shah, FE. Huggins, G.P. Huffman 2006: Microanalysis of ambient particles from Lexington, KY, by electron microscopy. - Atmospheric Environment, 40, pp. 651-663.

Cohen, D.R., N. F. Rutherford, E. Morisseau, A.M. Zissimos 2012: Geochemical patterns in the soil of Cyprus. - Science of the Total Environment, 420, pp. 250-262.

Craft, C.B., E.D. Seneca, S.W. Broome 1991: Loss on ignition and Kjeldahl digestion for estimating organic carbon and total nitrogen in estuarine marsh soils: calibration with dry combustion. Esturaies, 14, pp. 176-179.

DeLaeter, J.R., J.K. Böhlke, P.De Bievre, H. Hidaka, H.S. Peiser, K.J.R. Rosman, P.D.P. Taylor 2003: Atomic weights of the elements: Review 2000 (IUPAC Technical Report). - Pure and Applied Chemistry, 75, pp. 683-800.

DeVivo, B., R. Somma, R.A. Ayuso, G. Calderoni, A. Lima, S. Pagliuca, A. Sava 2001: Pb isotopes and toxic metals in floodplain and stream sediments from the Volturno river basin, Italy. Environmental Geology, 41, pp. 101-112.

Duong, T.T.T., B.K. Lee 2009: Partitioning and mobility behavior of metals in road dusts from national-scale industrial areas in Korea. - Atmospheric Environment, 43, pp. 3502-3509.

Farkas I., T. Weiszburg 2006: Mineralogical investigation of settled and airborne dust collected from Cluj County, Romania. - Földtani Közlöny, 136, pp. 547-572.

Feng, X.D., Z. Dang, W.L. Huang, C. Yang 2009: Chemical speciation of fine particle bound trace metals. - International Journal of Environmental Science and Technology, 6. pp. 337-346.

Fernandez Espinosa, A.J., M. Temero Rodriguez, FJ. Barragan de la Rosa, J.C. Jimenez Sanchez 2002 A chemical speciation of trace metals for fine urban particles. - Atmospheric Environment, 36, pp. 773-780.

Gautam, P., U. Blaha, E. Appel 2005: Magnetic susceptibility of dust-loaded leaves as a proxy of traffic-related heavy metal pollution in Kathmandu city, Nepal. - Atmospheric Environment, 39, pp. 2201-2211.

Graham, R.C., S.B. Weed, L.H. Bowen, S.W. Buol 1989: Weathering of iron-bearing minerals in soils and saprolite on the North Carolina Blue Ridge Front: I. Sand-size primary minerals. - Clays and clay minerals, 37, pp. 19-28.

Grobéty, B., R. Gieré, V. Dietze, P. Stille 2010: Airborne particles in the urban environment. Elements, 6, pp. 229-234.

Hjortekans, D.S., B.G. Bergbäck, A.V. Häggerud 2008: Transversal immission patterns and leachability of heavy metals in road side soils. - Journal of Environmental Monitoring, 10, pp. 739-746.

Komárek, M., V. Ettler, V. Chrastny, M. Mihaljevic 2008: Lead isotopes in environmental sciences: a review. - Environmental International, 34, pp. 562-577.

Köhler, J.S., F. Dufaud, E.H. Oelkers 2003: An experimental study of illite dissolution kinetics as a function of $\mathrm{pH}$ from 1.4 to 12.4 and temperature from 5 to $50{ }^{\circ} \mathrm{C}$. - Geochimica et Cosmochimica Acta, 67, pp. 3583-3594.

Laidlaw, M.A.S., G.M. Filippelli 2008: Resuspension of urban soils as a persistent source of lead poisoning in children: a review and new directions. - Applied Geochemistry, 23, pp. 2021-2039.

Mercier, G., J. Duchesne, A. Carles-Gibergues 2002: A simple and fast screening test to detect soils polluted by lead. - Environmental Pollution, 118, pp. 285-296.

Muxworthy, A.R., J. Matzka, A.F. Davila, N. Petersen 2003: Magnetic signature of daily sampled urban atmospheric particles. - Atmospheric Environment, 37, pp. 4163-4169.

Niu, J., P.E. Rasmussen, N.M. Hassan, R. Vincent 2010: Concentration distribution and bioaccessibility of trace elements in nano and fine urban airborne particulate matter: Influence of particle size. - Water, Air and Soil Pollution, 213, pp. 211-225.

Ódor, L., I. Horváth, U. Fügedi 1997: Low-density geochemical mapping in Hungary. - Journal of Geochemical Exploration, 60, pp. 55-66.

Panigrahy, P.K., G. Goswami, J.D. Panda, R.K. Panda 2003: Differential comminution of gypsum in cements ground in different mills. - Cement and Concrete Research, 33, pp. 945-947. 
Reiman, C., B. Flem, K. Fabian, M. Birke, A. Ladenberger, P. Negel, A. Demetradies, J. Hoogerwerf, The Gemas Project Team 2012: Lead and isotopes in agricultural soils of Europe - the continental perspective. - Applied Geochemistry, 27, pp. 532-542.

Rickard, D.T., J.E. Nriagu 1978: Aqueous environmental chemistry of lead. - In: Nriagu, J.O. (Ed.): The biogeochemistry of lead in the environment. Part A. Ecological cycles. Elsevier, New York, pp. 219-284.

Salma, I., W. Maenhaut, S. Dubtsov, É. Zemplén-Papp, Gy. Záray 2000: Impact of phase out of leaded gasoline on the air quality in Budapest. - Microchemical Journal, 67, pp. 127-133.

Silva, M., K. Kyser, D. Beauchemin 2007: Enhanced flow injection leaching of rocks by focused microwave heating with in-line monitoring of released elements by inductively coupled plasma mass spectrometry. - Analytica Chimica Acta, 584, 447-454.

Spear, T.M., W. Swee, J.H. Vincent, N. Stanisich 1998: Chemical speciation of lead dust associated with primary lead smelting. - Environmental Health Perspective, 106, pp. 565-571.

Sutherland, R.A. 2000: Bed sediment-associated trace metals in an urban stream, Oahu, Hawaii. Environmental Geology, 39, pp. 611-627.

Sutherland, R.A., F.M.G. Tack, A.D. Ziegler 2012: Road-deposited sediments in an urban environment: A first look at sequentially extracted element loads in grain size fractions. Journal of Hazardous Materials, 225-226, pp. 54-62.

Tarzia, M., B. DeVivo, R. Somma, R.A. Ayuso, R.A.R. McGill, R.R. Parrish 2002: Anthropogenic vs. natural pollution: An environmental study of an industrial site under remediation (Naples, Italy). - Geochemistry: Exploration, Environment, Analysis, 2, pp. 45-56.

Tokalioglu, S., S. Kartal 2006: Multivariate analysis of the data and speciation of heavy metals in street dust samples from the Organized Industrial District in Kayseri (Turkey). - Atmospheric Environment, 40, pp. 2797-2805.

Tomaševic, M., D. Antanasijevic, M. Anicic, I. Deljanin, A. Peric-Gjuric, M. Ristic 2013: Lead concentrations and isotope ratios in urban tree leaves. - Ecological Indicators, 24, pp. 504- 509.

Vardoulakis, S., B.E.A. Fisher, K. Pericleous, N. Gonzalez-Flesca 2003: Modelling air quality in street canyons: a review. - Atmospheric Environment, 37, pp. 155-182.

Vogelein, A., S. Pfister, A.C. Scheinhost, M.A. Marcus, R. Kretschmar 2005: Changes in zinc speciation in field soil after contamination with zinc oxide. - Environmental Science and Technology, 39, pp. 6616-6623.

Wichmann, H., R. Spenger, M. Wobst, M. Bahadir 2000: Combustion induced transport of heavy metals in the gas phase. A review. - Fresenius Environmental Bulletin, 9, pp. 72-125.

Young, T.M., D.A. Heeraman, G. Sirin, L.L. Ashbaugh 2002: Resuspension of soil as a source of airborne lead near industrial facilities and highways. - Environmental Science and Technology, 36, pp. 2484-2490.

Zajzon, N., E. Márton, P. Sipos, F. Kristály, T. Németh, V. Kovács Kis, T. Weiszburg 2013: Integrated mineralogical and magnetic study of magnetic airborne particles from potential pollution sources in industrial-urban environment. - Carpathian Journal of Earth and Environmental Sciences, 8/1, pp. 179-186. 